\title{
Hippuric acid excretion after benzylamine ingestion in man
}

\author{
S. G. WOOD, M. R. AL-ANI*, AND A. LAWSON \\ From the Department of Biochemistry, Charing Cross Hospital Medical School, University of London, \\ London W6 $8 R F$
}

ABSTRACT The fate of ${ }^{14} \mathrm{C}$-benzylamine after oral administration as the hydrochloride has been investigated in two male volunteers. Over $98 \%$ of the administered radiolabel was excreted in the urine as ${ }^{14} \mathrm{C}$-hippuric acid within 24 hours. The rate of urinary hippuric acid excretion was extremely rapid, with more than $90 \%$ of the dose excreted after three hours.

Benzylamine has a widespread use as a chemical intermediate for dyestuffs, pharmaceuticals, cosmetics and plastic polymers (Rose and Rose, 1966). It has also been employed in the manufacture of corrosion inhibitors (Yasnitskii et al., 1976; Makwana et al., 1975) and in photography (Starukhina et al., 1976). In spite of this, however, there appears to be a lack of knowledge of the biological fate in man of this ubiquitous chemical, although it has been over a century since interest was first shown in benzylamine metabolism. In 1877 Schmiedeberg fed benzylamine to dogs, and isolated hippuric acid from the urine, this finding being confirmed by Mosso (1890). Later, Imai (1924) showed that benzylamine was excreted by hens as benzoic acid and ornithuric acid, and by dogs as benzoic acid and hippuric acid.

In an attempt to fill this fundamental gap in our knowledge of benzylamine, the recently available ${ }^{14} \mathrm{C}$-benzylamine was used as the hydrochloride to follow the metabolism of this compound in two male volunteers.

\section{Materials and methods}

\section{${ }^{14}$ C-BENZYLAMINE}

Radiolabelled benzylamine was purchased from the Radiochemical Centre, Amersham, England, in the form of (methylene- ${ }^{14} \mathrm{C}$ ) benzylamine hydrochloride (specific activity $56 \mathrm{mCi} / \mathrm{mmol}$ ). The total radioactivity was diluted with distilled water to give a final solution containing $1.00 \mu \mathrm{Ci} / \mathrm{ml}$.

Unlabelled benzylamine hydrochloride was pre*Present address: Department of Biochemistry, College of
Medicine, University of Baghdad, Iraq.

Received for publication 12 April 1978

Accepted for publication 17 May 1978 pared by the dropwise addition of concentrated hydrochloric acid to a stirred solution of benzylamine in ether.

\section{LIQUID SCINTILLATION COUNTING}

A Packard Tricarb 3390 liquid scintillation counter was used for all radioactivity determinations. A dioxan-based scintillation cocktail was used, and efficiency of counting was determined by automatic external standardisation.

\section{DOSE ADMINISTRATION AND SAMPLE \\ COLLECTION}

Each ${ }^{14} \mathrm{C}$-benzylamine hydrochloride dose was prepared by dissolving unlabelled benzylamine hydrochloride $(100 \mathrm{mg})$ in $20 \mathrm{ml}(20 \mu \mathrm{Ci})$ aqueous ${ }^{14} \mathrm{C}$ benzylamine. After the two male volunteers had fasted overnight, they swallowed the benzylamine dose and the water that had been used to wash out the container several times. They ate a light breakfast one hour later, their urine was collected at timed intervals, the total volume measured and aliquots prepared for liquid scintillation counting.

\section{SAMPLE PREPARATION}

Samples of urine $(100 \mu l)$ were added directly to the scintillation cocktail $(10 \mathrm{ml})$ for radioactivity determinations. Aliquots of urine $(20 \mu \mathrm{l})$ were run on TLC plates pre-coated with silica gel 60 F524 (Merck) and followed by development with benzene/ acetic acid $(90 / 30, v / v)$. The areas corresponding to benzylamine, hippuric acid and benzoic acid (as indicated by quenching of fluorescence at $254 \mathrm{~nm}$ by these concurrently run reference compounds) were scraped from the plate separately and the finely ground silica prepared for counting. The remainder of the silica was scraped from the plate in $1 \mathrm{~cm}$ sections and also prepared for counting as above. 


\section{Results and discussion}

The percentage of an oral dose of ${ }^{14} \mathrm{C}$-benzylamine hydrochloride solution excreted in the urine at timed intervals is shown in the Table. The radioactivity in the urine was found, by TLC and subsequent liquid scintillation counting, to be associated with hippuric acid. No other radioactive metabolites were detected.

Table Urinary excretion of radioactivity following an oral dose* of ${ }^{14} \mathrm{C}$-benzylamine hydrochloride

\begin{tabular}{|c|c|c|c|c|}
\hline Subject & Time (hr) & $\begin{array}{l}\text { Total urine } \\
\text { volume }(\mathrm{ml})\end{array}$ & $\begin{array}{l}\text { Radioactivity } \\
\text { excreted per } \\
\text { time interval } \\
(\% \text { dose })\end{array}$ & $\begin{array}{l}\text { Cumulative } \\
\text { radioactivity } \\
\text { excreted } \\
(\% \text { dose })\end{array}$ \\
\hline $\mathbf{A}$ & $\begin{array}{c}0 \cdot 5 \\
1 \\
2 \\
3 \\
4 \\
5 \\
6 \\
7 \\
8 \\
10 \\
12 \\
24\end{array}$ & $\begin{array}{r}20 \\
16 \\
64 \\
45 \\
34 \\
25 \\
25 \\
25 \\
24 \\
50 \\
105 \\
630\end{array}$ & $\begin{array}{r}66.55 \\
17.62 \\
9.55 \\
2.42 \\
1.14 \\
0.49 \\
0.37 \\
0.23 \\
0.18 \\
0.20 \\
0.16 \\
0.29\end{array}$ & $\begin{array}{l}66 \cdot 55 \\
84 \cdot 17 \\
93 \cdot 72 \\
96 \cdot 14 \\
97 \cdot 28 \\
97 \cdot 77 \\
98 \cdot 14 \\
98 \cdot 37 \\
98 \cdot 55 \\
98 \cdot 75 \\
98 \cdot 91 \\
99 \cdot 20\end{array}$ \\
\hline B & $\begin{array}{l}0 \cdot 25 \\
0 \cdot 50 \\
1 \\
2 \\
3 \\
4 \\
5 \\
6 \\
7 \\
8 \\
9 \\
10 \\
12 \\
24\end{array}$ & $\begin{array}{r}50 \\
83 \\
92 \\
122 \\
130 \\
112 \\
90 \\
57 \\
39 \\
28 \\
36 \\
47 \\
120 \\
940\end{array}$ & $\begin{array}{r}3.02 \\
25.26 \\
37.84 \\
20.07 \\
4.56 \\
2.37 \\
1.29 \\
0.86 \\
0.57 \\
0.38 \\
0.33 \\
0.29 \\
0.35 \\
0.93\end{array}$ & $\begin{array}{r}3 \cdot 02 \\
28 \cdot 28 \\
66 \cdot 12 \\
86 \cdot 19 \\
90 \cdot 75 \\
93 \cdot 12 \\
94 \cdot 42 \\
95 \cdot 28 \\
95 \cdot 85 \\
96 \cdot 23 \\
96 \cdot 56 \\
96 \cdot 85 \\
97 \cdot 20 \\
98 \cdot 13\end{array}$ \\
\hline
\end{tabular}

*20 $\mu \mathrm{Ci}$ benzylamine hydrochloride $(100 \mathrm{mg})$.

After 24 hours, over $98 \%$ of the administered radioactivity had been recovered for both subjects. The excretion of the radiolabel was extremely rapid, with over $90 \%$ of the dose excreted in the first three hours following the administration of the benzylamine.

It is apparent from our results that benzylamine is rapidly metabolised, probably via benzylaldehyde, to benzoic acid, and finally excreted entirely as hippuric acid. This finding is in agreement with that of Bridges et al. (1970) who showed that, in man, benzoic acid was excreted in the urine exclusively as hippuric acid, $97 \%$ of the dose being eliminated within four hours of dosing. As there is so little difference in the excretion rate of hippuric acid derived from either benzylamine or benzoic acid, the metabolism of benzylamine to benzoic acid must be an extremely rapid process. Thus, although benzylamine is known to be a mucosal irritant, its rapid conversion to the harmless benzoic acid is of some relevance in assessing its overall toxicity.

In view of the importance of urinary hippuric acid excretion as an index of industrial exposure of workers to toluene (Pagnotto and Lieberman, 1967; Ikeda and Ohtsuji, 1969) it may be feasible for benzylamine exposure to be monitored similarly. However, interpretation of urinary hippuric acid determinations would be difficult where workers were exposed to these two chemicals simultaneously.

We are grateful to the Government of the Republic of Iraq, who completely financed this study, and to the University of Baghdad, who granted leave of absence for one of us (MRA).

\section{References}

Bridges, J. W., French, M. R., Smith, R. L., and Williams, R. T. (1970). The fate of benzoic acid in various species. Biochemical Journal, 118, 47-51.

Ikeda, M., and Ohtsuji, H. (1969). Significance of urinary hippuric acid determination as an index of toluene exposure. British Journal of Industrial Medicine, 26, 244-246.

Imai, T. (1924). Ueber das Verhalten des Benzylamins im Tierkoerper. Acta Scholae medicinalis universitatis in Kioto, 6, 415-9.

Makwana, S. C., Patel, N. K., and Vora, J. C. (1975). Influence of some amines as inhibitors towards corrosion of 3003 Aluminium in potassium persulphate solution. Transactions of the Society for the Advancement of Electrochemical Science and Technology, 10, 99-103.

Mosso, U. (1890). Quantitative Untersuchunger über die Ausscheidung der Salicylsäure und der Unwandlungsproducte des Benzylamins aus dem thierischen Organismus. Archiv für experimentelle Pathologie und Pharmakologie, 26, 267-278.

Pagnotto, L. D., and Lieberman, L. M. (1967). Urinary hippuric acid excretion as an index of toluene exposure. American Industrial Hygiene Association Journal, 28, 129134.

Rose, A., and Rose, E. (1966). Condensed Chemical Dictionary, 7th edition, p. 111 . Reinhold Publishing Corporation: New York.

Schmiedeberg, O. (1877). Ueber das Verhaltniss des Ammon. iaks und der primaren Monaminbasen zur Harnstoffbildung im Thierkörper. Archiv für experimentelle Pathologie und Pharmakologie, 8, 1-14.

Starukhina, N. V., Strelnikova, A. P., and Chebotereva, N. E (1976). Treatment of reversal colour photographic material. Tekhnika kino i televideniya, 10, 24-31.

Yasnitskii, B. G., Sarkisyanto, S. A., Korobeinikova, I. E., and Spivak, A. L. (1976). Studies of the inhibiting effect of some amine derivatives on steel corrosion by chloroacetaldehyde working solutions. Khimiko farmatsevticheskii zhurnal, 10, 107-110. 